\title{
Dual Burden of Malnutrition among Primary School Children in Myanmar
}

\section{Moh Moh Hlaing*, Mya Ohnamr, Sandar Tun, Thidar Khine, Wah Wah Win, Su Su Hlaing, Hla Phyo Linn, Khin Hnin Wint Phyu, Nyein Nyein Win}

Nutrition Research Division, Department of Medical Research, Ministry of Health and Sports, Yangon, Republic of the Union of Myanmar

Email: *mmhlaing73@gmail.com, ^mohmohhlaing@mohs.gov.mm

How to cite this paper: Hlaing, M.M., Ohnamr, M., Tun, S., Khine, T., Win, W.W., Hlaing, S.S., Linn, H.P., Phyu, K.H.W. and Win, N.N. (2021) Dual Burden of Malnutrition among Primary School Children in Myanmar. Food and Nutrition Sciences, 12, 115-123.

https://doi.org/10.4236/fns.2021.122010

Received: December 17, 2020

Accepted: February 15, 2021

Published: February 18, 2021

Copyright $\odot 2021$ by author(s) and Scientific Research Publishing Inc. This work is licensed under the Creative Commons Attribution International License (CC BY 4.0).

http://creativecommons.org/licenses/by/4.0/

\begin{abstract}
Background: The distribution of childhood nutritional diseases is shifting from a predominance of under nutrition to a dual burden of under- and over nutrition in low and middle income countries. Rapid economic development and urbanization lead to an increase in overweight and obesity and diet-related chronic diseases. The co-existence of under- and over nutrition is double burden and this is a public health challenge for community. Objective: To find out the nutritional status of primary school children. Method: The study was school based descriptive study and conducted during November 2014 to February 2015 in basic primary schools, basic middle schools and basic high schools in urban and rural area of Yangon, Mandalay, Taungyi and Mawlamyaing. A total of (2937) Grade IV and Grade V students were measured for weight, height and 592 students were measured for haemoglobin by standard equipment and standard procedure. Results: The overall prevalences of stunting, wasting, overweight, obesity and anaemia were $8.8 \%, 15 \%$, $4.6 \%$ and $3.1 \%$ and $36.1 \%$ respectively. The prevalences of stunting, over weight and obesity were more prevalent in boys and wasting and anaemia were more prevalent in girls. The result showed that the stunting was more prevalent in rural than in urban ( $7.5 \%$ in urban and $12.0 \%$ in rural). The prevalences of overweight and obesity were higher in urban than rural area (overweight $5.3 \%$ in urban and $2.8 \%$ in rural, obesity $3.8 \%$ in urban and $0.9 \%$ in rural). Children residing in urban area had higher anthropometric parameter than rural children. Conclusion: The present study observed the coexistence of obesity, overweight and undernourishment (wasting and stunting) among Myanmar School children. The findings highlighted the need for continued health promotion efforts to improve nutritional status of primary school children.
\end{abstract}




\section{Keywords}

Dual Burden, Malnutrition, Primary School Children

\section{Background and Justification}

The distribution of childhood nutritional diseases is shifting from a predominance of under nutrition to a dual burden of under- and over nutrition in low and middle-income countries. Rapid economic development and urbanization lead to an increase in overweight and obesity and diet-related chronic diseases. The co-existence of under- and over-nutrition is a double burden and this is a public health challenge for the community.

According to 2014 data, more than 1.9 billion 18 years and older adults worldwide, were overweight. More than 600 million were obese and 462 million were underweight. In the same year, 42 million children under 5 years old were overweight or obese. While 156 million were affected by stunting (low height-for-age) and 50 million children were affected by wasting (low weight-for-height) [1].

Nearly half of deaths in children under five was due to poor nutrition, while low- and middle-income countries simultaneously rise in childhood overweight and obesity increasing at a rate $30 \%$ faster than in richer nations. This double burden of malnutrition can exist at the individual level (e.g. obesity with deficiency of one or various vitamins and minerals). At the household level, when a mother may be overweight or anaemic and a child or grandparent is underweight; at the population level, where there is a prevalence of both under-nutrition and overweight in the same community, nation or region.

These are just some of the examples of biological mechanisms, which along with environmental and social influences, are increasingly understood as important drivers in the global burden of malnutrition across the life course.

The Double Burden of Malnutrition (DBM) affects all countries, rich and poor. At the population level, women are most affected by the DB and overweight is prevalent than underweight women in most countries. The prevalence of DBM at the household level, with stunted children coexisting with overweight/obese women, is generally below 10 percent and is most commonly found in Latin American countries. At the individual level, the most common form of DBM seems to be energy over nutrition and iron deficiency, a combination that is found even in the United States [2].

In 2010, the global prevalence rate of malnutrition among 5 - 14 years old school-age children prevalence of stunting, was approximately 28\% (171 million children) according to the Growth and Assessment Surveillance Unit of the WHO [3].

The overall prevalence of stunting was between $48 \%$ - 52\% with an overall prevalence of underweight which was between $34 \%-62 \%$ among school-age children from developing countries. 
The SCN notes that among school-age children stunting and underweight are more prevalent than wasting. Simultaneously, childhood rates of obesity have increased dramatically [4].

Although the prevalence is higher in developed countries, developing countries have greater absolute numbers of affected children and higher relative increases. Because of rapid economic development and urbanization, energy dense diets replace traditional diets due to nutrition transition. This has lead to an increase in overweight and obesity and diet-related chronic diseases. The coexistence of under- and over nutrition is double burden and this is a public health challenge for community.

Although an increased prevalence over weight obesity (OW/OB) was initially detected among adults [5], it is also emerging as a public health issue for children and adolescents in transitional countries including Myanmar. Child and adolescent obesity is a strong predictor of adult obesity [6], and the risk of OW/OB in this age group is increased if one or both parents is OW/OB [6] [7]. Prevalence estimates vary considerably depending on the country.

Since OW/OB children are prone to becoming OW/OB adults [6] they are also at high risk of non-communicable diseases in later life [8]. Besides, the rise in adolescent $\mathrm{OW} / \mathrm{OB}$ has been matched by an increase in metabolic syndrome in this age group, a major risk factor to develop chronic disease [9].

In Myanmar, there is limited source of magnitude of nutritional status of primary school children and research done on nutritional status of primary school children were only small scale survey. Therefore, this study aims to assess the magnitude of the problem of malnutrition (both under nutrition and over nutrition) among the primary school children.

\section{Materials and Method}

\subsection{Study Design}

The study design was cross sectional descriptive study.

\subsection{Study Place and Time}

The study was conducted in 17 Basic Education Primary Schools, Basic Education Middle Schools and Basic Education High Schools in downtown, peri-urban and rural area from Yangon, Mandalay, Mawlamyaing and Taunggyi during November 2014 to February 2015.

\subsection{Study Population}

Grade IV and Grade V primary school children from selected schools.

\subsection{Sample Size Calculation}

Using the data on prevalence of underweight among primary school children in Yangon Region 40\% (2009) [10], sample size will be 369, and calculated as follows. 


$$
n=\frac{1.96 \times 1.96 \times p q}{d^{2}}=369
$$

(Confidence level 95\% and absolute relative precision of 5\%).

In each Township 390 female students and 390 male students will be recruited. Therefore total sample size is $3120(780 \times 4$ townships $)$.

\subsection{Sampling}

To get representative data on nutritional status of primary school children, one capital township from four regions of Myanmar (Delta, Costal, Plain and Hilly regions) was chosen. Yangon for Delta region, Mandalay for Plain region, Mawlamyaing for Coastal region and Taunggyi for Hilly region were chosen purposively. Six schools from Yangon, three schools from Mandalay, four schools from Taungyi and four schools from Mawlamyaing were chosen to get required sample size depend upon number of Grade IV and Grade V students in selected schools with the help of township education officer in each township. With the help of Headmasters /Headmistress and teachers, Grade IV and Grade V students were chosen to participate in the study. All Grade IV and Grade V students in each selected were measure for height and weight. Primary schools with school milk programme were excluded. Every $5^{\text {th }}$ student were checked for haemoglobin level from finger tip blood with Haemocue 201. A total of 592 students were measured.

\subsection{Method}

Informed consents from children and parents of all selected primary school were taken. School children who do not want to participate in this research will be excluded.

Interviewers have been trained for interviewing questionnaires and anthropometric measurements with standard methods. Background characteristics of children were assessed by structured questionnaire. Height, weight of 2937 students school children were measured by standard procedure. The weight of students will be measured in kilogram by using Seca bathroom scale without wearing slippers and heavy clothes, reading is taken for nearest $0.1 \mathrm{~kg}$. Height of the school children was measured by height measuring tape (Seca body meter 206) and waist circumferences of school children were measured with Seca 201.

For the assessment of child nutritional status, child who has a Z-score of height-for-age, BMI-for-age below $(\times 2 \mathrm{SD})$ of the median of the WHO reference population was considered as stunted and wasted) respectively. A Z-score for BMI-for-age above $(+1 \mathrm{SD})$ and $(+2 \mathrm{SD})$ of the median of the WHO reference population was defined as overweight and obesity respectivel [11]. The anaemia cut-off for 5 - 11 years old children is less than $11.5 \mathrm{~g} / 1$ [12].

All the haemoglobin results were informed to the teachers and the parents. Children with anaemia were treated with iron supplement and children with severe anaemia were transferred to School Health Medical Officer. 


\section{Data Entry and Analysis}

Data entry and analysis was done with Epi Data and SPSS 11.0 Univariate categorical was presented with frequency and percent tables and that of continuous variables was presented with mean \pm SD. Statistical significance was set at $\mathrm{P}<$ 0.05 .

\section{Ethical Considerations}

The proposal was approved by the Institutional Ethical Review Committee, Department of Medical Research.

\subsection{Findings}

1) Background characteristics of primary school children

Among 2937 primary school students, $52.0 \%$ and $48.0 \%$ of students were boys and girls respectively. The mean age of the boy and girl students were $9.61 \pm 0.95$ years with minimum 7.1 years and maximum 16.6 years.

Table 1 illustrated that more than half of the school children were boys and Grade V students.

Table 2 described the anthropometric parameter of the children, children residing in urban area had higher anthropometric parameter than rural children and that of boys are higher than girls.

Table 3 showed that the overall prevalence of wasting, stunting, overweight, obesity and aneaemia were $15.0 \%, 8.8 \%, 4.6 \%, 3.1 \%$ and $36.1 \%$ respectively. The prevalence of stunting, over weight and obesity were more prevalent in boys and wasting and anaemia were more prevalent in girls.

In Table 4, the stunting was more prevalent in rural than in urban and the overall prevalence of wasting was not much different in urban and rural. The prevalence of overweight and obesity was higher in urban than rural area.

Figure 1 illustrated that the mean haemoglobin level of boys did not different Table 1. Distribution of primary school children by Township.

\begin{tabular}{cccccc}
\hline & $\begin{array}{c}\text { Yangon } \\
(\mathbf{n}=728)\end{array}$ & $\begin{array}{c}\text { Mandalay } \\
(\mathbf{n}=764)\end{array}$ & $\begin{array}{c}\text { Taungyi } \\
(\mathbf{n}=730)\end{array}$ & $\begin{array}{c}\text { Mawlamyaing } \\
(\mathbf{n}=715)\end{array}$ & $\mathbf{N}=2937$ \\
Sex & & & & & \\
Boys & $382(52.5 \%)$ & $382(50.0 \%)$ & $387(53.0 \%)$ & $376(52.6 \%)$ & $1527(52.0 \%)$ \\
Girls & $346(47.5 \%)$ & $382(50.0 \%)$ & $343(47.0 \%)$ & $339(47.4 \%)$ & $1410(48.0 \%)$ \\
\hline Standard & & & & & \\
Grade IV & $392(53.8 \%)$ & $351(45.9 \%)$ & $322(44.1 \%)$ & $368(51.5 \%)$ & $1433(48.8 \%)$ \\
GradeV & $336(46.2 \%)$ & $413(54.1 \%)$ & $408(55.9 \%)$ & $347(48.5 \%)$ & $1504(51.2 \%)$ \\
\hline Urban & $310(42.5 \%)$ & $234(30.6 \%)$ & $271(37.1 \%)$ & $312(43.6 \%)$ & $1127(38.4 \%)$ \\
Peri-urban & $211(29.0 \%)$ & $320(41.9 \%)$ & $263(36.0 \%)$ & $217(30.3 \%)$ & $799(27.2 \%)$ \\
Rural & $207(28.4 \%)$ & $210(27.5 \%)$ & $196(26.8 \%)$ & $186(26.0 \%)$ & $1011(34.4 \%)$ \\
\hline
\end{tabular}


Table 2. Anthropometric measurements of primary school children.

\begin{tabular}{|c|c|c|c|c|}
\hline & Sex & $\begin{array}{l}\text { Mean height } \\
\text { (SD) } \mathrm{cm}\end{array}$ & $\begin{array}{l}\text { Mean weight } \\
\text { (SD)Kg }\end{array}$ & $\begin{array}{l}\text { Mean BMI } \\
(\mathrm{SD}) \mathrm{Kg} / \mathrm{m}^{2}\end{array}$ \\
\hline \multirow[t]{2}{*}{ Yangon } & Boys & $132.6(6.9)$ & $28.4(7.7)$ & $15.9(3.1)$ \\
\hline & Girls & $131.8(6.8)$ & $26.5(6.3)$ & $15.1(2.6)$ \\
\hline \multirow[t]{2}{*}{ Mandalay } & Boys & $131.1(6.9)$ & $25.8(5.9)$ & $14.9(2.2)$ \\
\hline & Girls & $131.5(7.5)$ & $25.9(5.6)$ & $14.9(2.2)$ \\
\hline \multirow[t]{2}{*}{ Taungyi } & Boys & $131.1(7.3)$ & $26.8(5.6)$ & $15.4(1.9)$ \\
\hline & Girls & $130.2(7.0)$ & $26.0(5.4)$ & $15.2(1.9)$ \\
\hline \multirow[t]{2}{*}{ Mawlamyaing } & Boys & $131.3(7.5)$ & $27.0(6.9)$ & $15.5(2.8)$ \\
\hline & Girls & $130.2(7.0)$ & $27.1(6.3)$ & $15.2(2.4)$ \\
\hline \multirow[t]{2}{*}{ Urban } & Boys & $131.6(6.6)$ & $27.1(6.3)$ & $5.4(2.7)$ \\
\hline & Girls & $131.8(6.9)$ & $26.7(6.1)$ & $5.2(2.4)$ \\
\hline \multirow[t]{2}{*}{ Rural } & Boys & $131.6(7.6)$ & $26.8(6.2)$ & $15.3(2.1)$ \\
\hline & Girls & $130.3(6.9)$ & $25.4(5.1)$ & $15.2(2.4)$ \\
\hline \multirow[t]{2}{*}{ Total } & Boys & $131.6(6.9)^{\star}$ & $26.9(6.6)^{* \star}$ & $15.4(2.6)^{\star *}$ \\
\hline & Girls & $131.4(6.9)$ & $26.4(5.9)$ & $15.1(2.3)$ \\
\hline \multirow[t]{2}{*}{ Total } & Urban & $131.7(6.7)^{* *}$ & $26.9(6.4)^{* *}$ & $15.3(2.6)^{* *}$ \\
\hline & Rural & $130.9(7.3)$ & $26.1(5.7)$ & $15.0(2.0)$ \\
\hline
\end{tabular}

${ }^{*} \mathrm{P}<0.05 .{ }^{*} \mathrm{P}<0.0$

Table 3. Distribution of nutritional status of primary school children by sex.

\begin{tabular}{cccccc}
\hline & Stunting & Wasting & Overweight & Obesity & Anaemia \\
\hline Boys & $9.1 \%$ & $14.1 \%$ & $5.1 \%$ & $4.0 \%$ & $32.8 \%$ \\
Girls & $8.5 \%$ & $16.1 \%$ & $4.0 \%$ & $1.9 \%$ & $39.5 \%$ \\
Total & $8.8 \%$ & $15.0 \%$ & $4.6 \%$ & $3.1 \%$ & $36.1 \%$ \\
\hline
\end{tabular}

Table 4. Distribution of nutritional status of primary school children according to urban and rural.

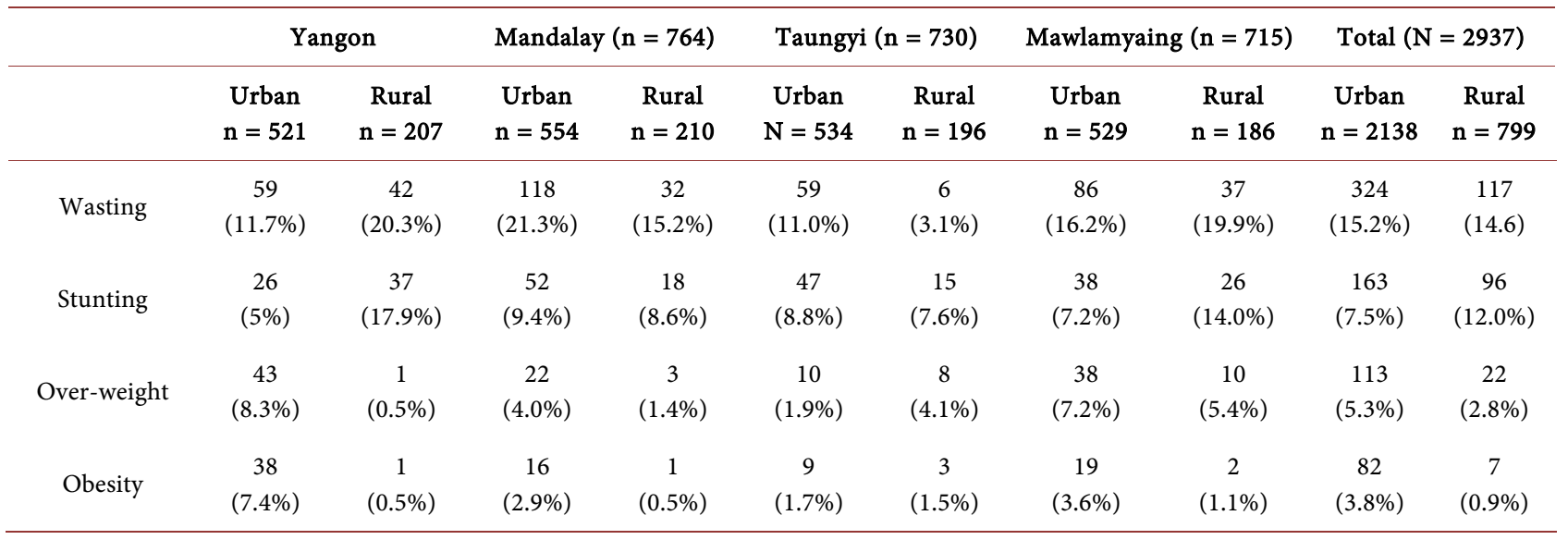

from that of the girls. The mean (SD) haemoglobin level of boys was 11.9 (1.0) $\mathrm{g} / \mathrm{dL}$ and that of girls was $11.7(1.0) \mathrm{g} / \mathrm{dL}$. 


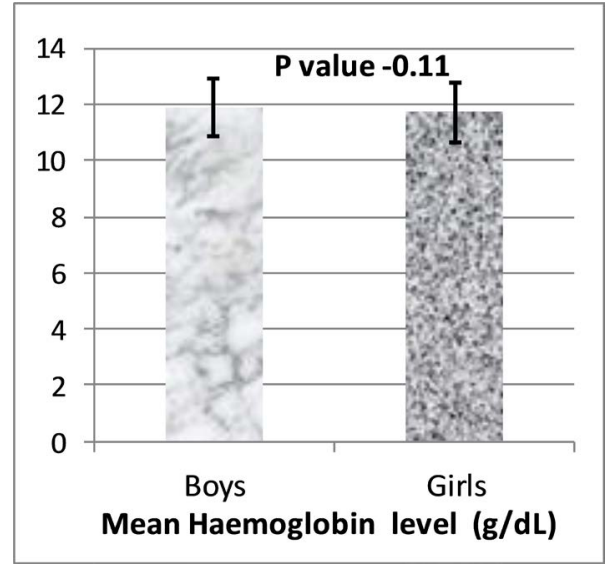

Figure 1. Mean hamemoglobin level according to sex of primary school children.

\subsection{Discussion}

The present study revealed that the coexistence of under-nutrition and over-nutrition among school children in an urban and rural area of Myanmar. The overall prevalence of stunting, wasting, overweight and obesity and anaemia was $8.8 \%, 15 \%, 4.6 \%, 3.1 \%$ and $36.1 \%$ respectively.

The study conducted in Hlaing Thar Yar township, Yangon Region in 2006, the prevalence of stunting, wasting and anaemia among primary school children were $28.9 \%, 39.9 \%$ and $58.8 \%$ respectively [13]. In 2010, the prevalence of stunting, thinness and overweight among peri-urban school children were 19.7\%, $46 \%$ and $2.6 \%$ in Hlaing tharyar township [14]. The prevalence of stunting, wasting and anaemia was high in the previous study in Hlaing tharyar township because Hlaing tharyar township is an urban slum of Yangon Region and most of the population residing at that are were low socioeconomic status.

The result showed that the stunting was more prevalent in rural than in urban (7.5\% in Urban and $12.0 \%$ in rural). This result was similar to the Vietnamese school children in SEANUTS study in 2011 (8.9\% in urban and $17.7 \%$ in rural) [15]. Prevalence of wasting was also higher in rural than urban in Vietnamese children [15]. In this study, the overall prevalence was not much differed in urban and rural (15.2\% in urban and $14.6 \%$ in rural). The prevalence of malnutrition was higher in rural than urban especially stunting. These results agree with Senger and Hamulka (1998): the nutrition status of town children was better than that of rural children [16].

The prevalence of overweight and obesity was higher in urban than the rural area (Prevalence of overweight and obesity were 5.3\% and 3.8\% in urban and $2.8 \%$ and $0.9 \%$ in rural). This finding was also similar with the SEANUTS study in Vietnam, nearly $29 \%$ of the Vietnamese urban children were either overweight or obese when compared with $4 \%$ of the overweight children and $1.6 \%$ of the obese children in the rural areas [15]. The findings of this study heightened that over-nutrition was an urban phenomenon but the dual burden was found in both urban a rural area of different four regions. 
The result of the prevalence of anaemia was $36.1 \%$ and it indicated that this situation was in moderate public health significance among populations [12]. The prevalence was a little bit higher in girls than boys but the mean haemoglobin level was not much different. This finding was in agreement with the SEANUTS study in Vietnam but the public health importance of anaemia in this study was in the mild category [12] [15].

The values of all the anthropometric parameters were significantly higher for urban children than for rural children $(\mathrm{p}<0.01)$. All the anthropometric parameters of the boy were significantly higher than that of girls $(\mathrm{P}<0.05$ for mean height and $\mathrm{P}<0.01$ for mean weight and $\mathrm{BMI})$. The same findings were also found in the Vietnamese school children in SEANUTS study [15].

To summarize, until recently, Myanmar has considered undernutrition to be a major problem, and nutrition supplementation has been the key intervention. The present study observed the coexistence of obesity, overweight and undernourishment (wasting and stunting) among Myanmar school children.

\section{Conclusions and Recommendations}

In conclusion, the findings from this study can provide baseline data for nutrition surveillance among primary school children and also provide comparable data on the nutritional status (undernutrition and obesity) of primary school children within the South East Asia region. Further longitudinal surveillance should be done and will provide a better insight into this issue and will help define the trends of malnutrition among primary school children in Myanmar. This study can help the surveillance effort to address the double burden of malnutrition that is emerging that needs to be concurrently addressed.

The majority of these initiatives and efforts are aimed at 5-year-old children, in line with the recommendations of the UN agencies. Evidence-based research clearly states that the most cost-effective interventions with long-term potential are those targeting early child development [17]. The strategy for the prevention and management of malnutrition among school children should be implemented. Intervention should be strengthened to address the double burden of malnutrition across the life-course not only on undernutrition. Recommendations for strategies to address the DBM, adaptable to the country-specific trend are needed.

\section{Limitation of the Study}

The prevalence of malnutrition from this study could not represent the overall nutritional status of schoolchildren in Myanmar because the study was conducted in four capital cities to represent the geographical regions of Myanmar.

\section{Conflicts of Interest}

The authors declare no conflicts of interest regarding the publication of this paper. 


\section{References}

[1] WHO (2014) Double Burden of Malnutrition.

[2] Shrimpton, R. and Rokx, C. (2012) The Double Burden of Malnutrition: A Review of Global Evidence. https://doi.org/10.1596/27417

[3] Standing Committee on Nutrition (2002) School Age Children Their Health and Nutrition. SCN News (25), 1-78.

[4] de Onis, M., Blossner, M. and Borghi, E. (2012) Prevalence and Trends of Stunting among Pre-School Children, 1990-2020. Public Health Nutrition, 15, 142-148. https://doi.org/10.1017/S1368980011001315

[5] Popkin, B. (2006) Global Nutrition Dynamics: The World Is Shifting Rapidly toward a Diet Linked with Noncommunicable Diseases. The American Journal of Clinical $\mathrm{Nu}$ trition, 84, 289-298. https://doi.org/10.1093/ajcn/84.2.289

[6] Shetty, P.S. (2002) Nutrition Transition in India. Public Health Nutrition, 5, 175-182. https://doi.org/10.1079/PHN2001291

[7] Mo-suwan, L., Tongkumchum, P. and Puetpaiboon, A. (2000) Determinants of Overweight Tracking from Childhood to Adolescence: A 5y Follow-Up Study of Hat Yai Schoolchildren. International Journal of Obesity, 24, 1642-1647. https://doi.org/10.1038/sj.ijo.0801432

[8] Must, A. and Strauss, R.S. (1999) Risks and Consequences of Childhood and Adolescent Obesity. International Journal of Obesity, 23, s2-s11. https://doi.org/10.1038/sj.ijo.0800852

[9] Kelishadi, R. (2007) Childhood Overweight, Obesity and the Metabolic Syndrome in Developing Countries. Epidemiologic Reviews, 29, 62-76. https://doi.org/10.1093/epirev/mxm003

[10] Thwin, T., Ohnmar, M., Tun, S., et al. (2011) Intake of Nitrites and Nitrates from Processed Meats by Primary School Children. Myanmar Health Research Congress, Program and Abstracts, 17.

[11] WHO (2006) Child Growth Standard. Geneva.

[12] WHO (2011) Haemoglobin Concentrations for the Diagnosis of Anaemia and Assessment of Severity. Vitamin and Mineral Nutrition Information System. World Health Organization, Geneva, WHO/NMH/NHD/MNM/11.1.

[13] Oo, A.A. (2003) Nutritional Anemia among Primary School Children in Hlaing-Thar-Yar Township of Yangon Division. MMedSc Thesis (Public Health), Institute of Medicine, Yangon.

[14] Wai, C.S. (2010) Worm Infestations and Nutritional Status among Primary School Children in Peri-Urban Area of Hlaingtharya Township. MPH Thesis, University of Public Health, Yangon.

[15] Nguyen, B.K.L., Thi, H.L., Nguyen Do, V.A., Thuy, N.T., et al. (2013) Double Burden of Undernutrition and Overnutrition in Vietnam in 2011: Results of the SEANUTS Study in 0.5-11-Year-Old Children. British Journal of Nutrition, 110, S45-S56. https://doi.org/10.1017/S0007114513002080

[16] Senger and Hamulka. Comparative Study of Nutritional Status of Urban and Rural School Girl's Children Khartoum State, Sudan. In Fatima Omer Nabag Department of Family \& Community Science, Faculty of Agricultural Studies, Sudan University of Science and Technology, Shambat, Khartoum North, Sudan.

[17] Grantham-McGregor, S. (2002) Linear Growth Retardation and Cognition. The Lancet, 359, 542. https://doi.org/10.1016/S0140-6736(02)07719-X 